\title{
Product Traceability along the Agri-Food Chain: How to Implement It and Measure the Company Performances
}

\author{
Stefano Farné \\ Department of Electrical, Computer and Biomedical Engineering, University of Pavia, Italy.
}

DOI: http://doi.org/10.46382/MJBAS.2020.4408

Copyright: (92020 Stefano Farné. This is an open access article distributed under the terms of the Creative Commons Attribution License, which permits unrestricted use, distribution, and reproduction in any medium, provided the original author and source are credited.

There is no doubt that consumers play an increasingly decisive role in determining the success or the failure of a food product; their focus has expanded from only perceivable product requirements, to the satisfaction of those intangible characteristics that are represented by non-explicit requirements, such as safety, healthiness, legality, respect for the environment. This cultural evolution has been acknowledged by the European Union, which has included traceability as a cornerstone in the regulations on food safety. In fact, starting from 1st January 2005 the provisions of the Regulation (EC) 178/2002 concerning food safety came into force. The Regulation obliges food and feed business operators to keep information on their suppliers (from whom they bought what and in what quantity) and on their customers (to whom they sold what and in what quantity). Consumers are not the only interested party for an agri-food company: in fact, regulatory bodies, control authorities and suppliers, on whose quality the quality of food products depend, must also be considered. Determining in a quantitative way the degree of satisfaction of the various categories of stakeholders and being able, at the same time, to evaluate their performance, represents a useful study to guide the implementation of European legislation on the traceability of food products. This process needs to be as effective and efficient as possible, avoiding spending time and resources on activities of lesser importance and helping to clarify the objectives to be achieved. From the considerations made, a methodological study was derived with the aim of identifying the Key Performance Indicators (KPIs) induced by the legislation through which measure the level of performance of companies and the degree of satisfaction of their stakeholders. The approach adopted and the conclusions reached are the topics of this paper.

Keywords: Traceability, Food, Agri-Food Chain, Supply Chain, Corporate Performance Management, KPI, Retrieval

\section{Introduction}

The Regulation 178/2002, applied starting from $1^{\text {st }}$ January 2005, was created mainly to "guarantee a high level of protection of human life and health", with the aim of creating the conditions for the free circulation of food products in respect for the social and economic interests of individuals. Furthermore, following the enlargement of the European Union, the free movement of products between the different Member States can only be achieved if "the safety requirements of food and feed do not differ significantly from one Member State to another". In fact, the adoption of non-homogeneous procedures by the various states could create uneven conditions of competition and have a direct impact on the functioning of the internal market. In order to safeguard the health of citizens and make decision-making processes credible in the context of food law, provisions must be put in place to ensure that unsafe foods are not placed on the market. Furthermore, it is necessary to set up mechanisms through which identify the presence and causes of food safety problems and define policies for resolving any problems. From this derives, first of all, the need to consider the entire food production chain from an integrated perspective. Various experiences in the field of food production, then, have shown that "the impossibility of reconstructing the path taken by food and feed can endanger the functioning of the market for these products". The need was therefore identified to "prepare a general system for the traceability of products that encompasses the feed and food sector, in order to be able to carry out targeted and precise withdrawals or provide information to consumers or officials responsible for controls". Article 18 of Regulation 178 provides, in fact, the traceability defined by the same 
regulation as the "... possibility of reconstructing and following the path of a food, a feed, an animal intended for food production or a substance intended or able to become part of a food or feed through all stages of production, transformation and distribution" at every stage of the food chain, from production, to transformation, to distribution. The need for an integrated analysis of the entire food chain derives from the fact that traceability, in the event of an investigation, must be guaranteed at each stage of processing. The implementation of this legislation within companies operating in the food sector requires an analysis and review of their production processes and information flows. In addition to this analysis, the rules and customs governing the relationships between the company and the other players making up the food production process must also be reviewed. In fact, it is necessary to note a change in customer expectations that leads companies to change the strategies aimed at satisfying them and a change in the needs of suppliers that goes at the same time with the raising of the level of service that they must offer to the company. Similarly, the application of this legislation also affects the tasks that must be performed by the staff employed in the company. The figures involved in these changes represent a subset of the group of corporate stakeholders, as well as the elements making up the supply chain. Continuing the analysis along this line, it appears evident that even a Regulator, in this case represented by the European Union, must be counted among the company stakeholders. To support these hypotheses there are some new approaches, like the Performance Prism (Neely A., Adams C.) to the problem of Corporate Performance Management (CPM) which identify a new category of stakeholders in the Legal Community and in the Regulators.

\section{Regulatory framework}

The food production market has undergone deep transformations in recent decades: large-scale production, production areas increasingly distant from the places of consumption of the product, globalization and expansion of markets, new technologies incorporated in products, greater health concerns of the consumer, greater propensity of the consumer to make an informed choice, the need to manage business risk. All this has created new demands and new needs in the sector, which have been acknowledged by the regulatory bodies. The main European and Italian regulations currently in force to guarantee food safety are the following:

- The Italian law n. 283 of 1962 (subsequently updated) allowed the prosecution of food fraud and adulteration while supervising to protect public health. About forty years later, the integrated strategy of the European Union on food safety has identified the same objective as primary: to ensure that "safe" food reaches the consumer. The path leading to food safety is complex and implies the active participation of all the players in the food chain, including the consumer.

- The basic European standards, as regards the regulation of feed and food, are contained in EC regulation no. 178/2002 of the European Parliament and of the Council, of 28 January 2002, which establishes the general principles and requirements of food law, establishes the European Food Safety Authority (EFSA), establishes procedures in the field of food safety and is the fulcrum from which comes an entire "hygiene package" of community regulations (EC regulation no. 852/2004, EC regulation no. 853/2004, EC regulation no. 854/2004, EC regulation no. 882/2004 and Directive 2002/99): 
- Regulation (EC) No. 852/2004 OF THE EUROPEAN PARLIAMENT AND OF THE COUNCIL of 29 April 2004 on the hygiene of food products.

○ Regulation (EC) No. 853/2004 OF THE EUROPEAN PARLIAMENT AND OF THE COUNCIL of 29 April 2004 establishing specific hygiene rules for food of animal origin.

- Regulation (EC) No. 854/2004 OF THE EUROPEAN PARLIAMENT AND OF THE COUNCIL of 29 April 2004 establishing specific rules for the organization of official controls on products of animal origin intended for human consumption.

○ Regulation (EC) no. 882/2004 which represents the framework standard for the organization of official controls on food, feed, animal health and welfare. Checks that must be carried out periodically, based on a risk assessment and with appropriate frequency, to achieve the objectives defined by the regulation.

- Regulation (EC) 183/2005, which establishes the requirements for feed hygiene.

The EC regulation 2073/2005 with subsequent amendments and additions is aimed at all operators in the food sector (FBO) who operate in the various stages of the supply chain such as processing, manufacturing, handling including the retail and distribution stage. Its reading must be done keeping in mind the concepts and the preventive approach "from farm to fork" for food safety.

More specific regulations govern animal nutrition (PNAA), the control of zoonoses, the search for residues in animals and products of animal origin (PNR).

UNI 10939: 2001 standard "Traceability systems in agri-food chains - General principles for design and implementation" with the aim of providing useful elements for the design and management of a supply chain traceability system. The UNI 10939: 2001 standard, which applied only to phases of the supply chain connected by contractual relationships, did not prescribe how extensive and profound the traceability of a food should be, but left the possibility of choice both in terms of the characteristics to be tracked and in this regard. The depth and breadth of the supply chain that was intended to be considered. UNI 10939 and Reg. 178 have never been "superimposable" as they had different objectives and requirements. Regulation 178 does not require the development of a System (... which must be designed, implemented, maintained effective through the use of human and instrumental resources) but simply to collect information on certain aspects. UNI 10939 has been replaced by the international standard ISO 22005.

UNI EN ISO 22005 standard issued in 2008 "Traceability in agri-food chains - General principles and basic requirements for design and implementation systems" applies to supply chain traceability and internal traceability. The certification against UNI EN ISO 22005 is "expendable" on a commercial level as it is an international standard, applied and recognized all over the world.

\section{Conceptual framework}

Regulation 178/2002 represents the basic provision on food safety through which the aim is to reform food legislation to ensure, first of all, a high level of health protection (Coscia, 2002). Using this regulation, the general 
principles that the internal legislators must respect in defining the future discipline, some requirements for the operators of the sector and the essential requirements of food and feed are established. Within the legislation, the definition of food is of particular importance. It is indispensable to allow uniform application of food law throughout Europe. A food is any processed, partially processed, or unprocessed substance or product that can be ingested or that is reasonably expected to be ingested by humans. The legislation affects the food chain in its entirety and in every phase, from procurement, through transformation, to the distribution of the product to the customer. The principle on which it is based provides that, in the area of food safety, the responsibility lies mainly with operators in the sector, who are obliged not to place risky products on the market. The definition of the risk, provided by the legislation, is based on scientific criteria by means of which the risk is a function of the probability and severity of an adverse effect on health, resulting from the presence of a hazard. Furthermore, a product is defined at risk even in the event that the information provided to the customer, in order to guide him in its correct use, is not suitable. The concept of risk is tempered by the introduction of the precautionary principle, referring to which, while respecting the compliance requirements, a product may be subject to restrictions relating to its placing on the market if there are reasons to suspect that the food is not sure. The objective, clear and transparent definition of the concept of risk aims at increasing the level of safety perceived by consumers. The agri-food world, in fact, must remedy the situation of insecurity induced by epidemics that have affected the animal world and, at the same time, must prevent the risk that consumers perceive as a danger the possibility of buying food products from countries considered underdeveloped compared to Western European standards. Based on a less rigorous approach, the concept of risk has represented, even in the past, an element that companies in the agri-food sector had to take into consideration. The challenge for companies operating in the sector, on the other hand, is represented by the implementation of the procedure by which to pursue the traceability of the products placed on the market. In order to reduce products at risk and, above all, with a view to reduce the time needed to implement corrective actions following problems encountered, the European Union has required companies to equip themselves with a management system and tools through which it is possible to carry out the traceability of the products. The term traceability means the ability of the food sector "to identify who has provided them with a food, a feed, an animal intended for food production or any other substance intended or capable of entering a distant part of a food or feed". In addition, the legislation provides that "food or feed, that is placed on the Community market or that is likely to be, must be properly labeled or identified to facilitate its traceability." The commitment required to the companies, to meet these requirements, is particularly onerous, in how much invests their production processes, the information flow that underlies them, their relationships with suppliers and their relationship with customers. If, then, we consider the fact that many Italian companies operating in the food sector belong to the category of Small and Medium-sized enterprises (SMEs), within the majority of which, the information flow management is approximate and not very effective, the extent of the effort they have to face is better understood. A correct procedure that allows reaching an effective and efficient traceability of the products must follow the guidelines of the Corporate Performance Management. Using the approach suggested by the CPM, in fact, the set of entities external to the company interested, for different reasons, in the problem under consideration is initially identified. From the analysis of their needs, the objectives that must be pursued are deduced and based on them, 
efforts are made to ensure that the necessary conditions are met within the company to achieve these objectives. The introduction of the traceability legislation has led to a change in the group of subjects making up the set of stakeholders and their attention. These aspects have repercussions on the definition of objectives and consequently on the whole process to achieve the traceability of the products. In the scientific literature there are many studies that refer to food traceability. Focusing on the Italian case, certainly representative but also extendable to other countries, the following scientific papers are cited: (Barge et al.) on the RFID solutions for logistics units management in the food supply chain, (Barge et al.) on the use of passive ultra high frequency radio frequency identification systems for single-item identification in food supply chains, (Comba et al.) about the open problems in food products traceability, (Giametta et al.) exposing an integrated technological traceability model in the olive growing production chain.

\section{Corporate Performance Management}

Gartner Group defines the Corporate Performance Management "the methodologies, metrics, processes and systems used to monitor and manage the business performance of an enterprise" (figure 1).

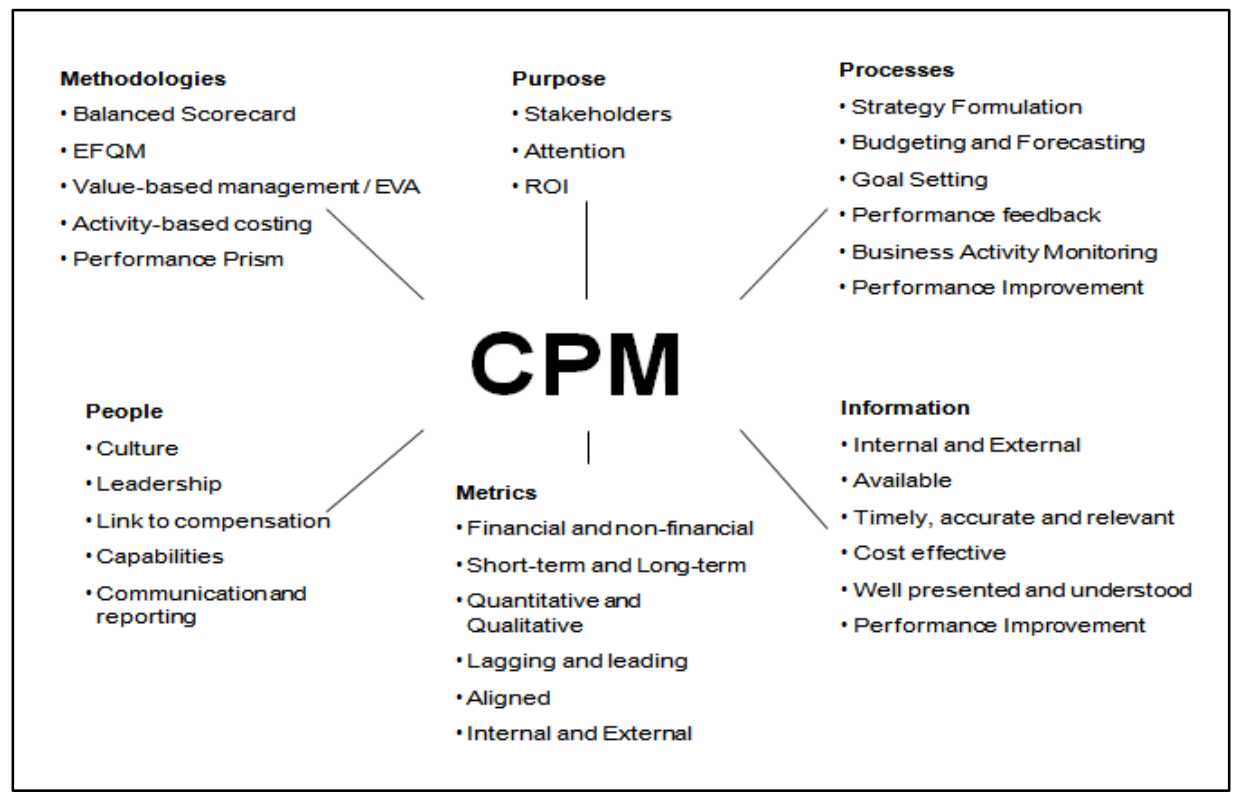

Fig.1: Definition of Corporate Performance Management

The concept of Corporate Performance Management has evolved over the years. At the beginning of the 90s, CPM systems were focused on analyzing the balance sheet as companies were particularly attentive to information regarding their financial management. During the mid-90s, the interest of companies expanded and also involved the creation of strategies and success maps through which to correlate key business objectives so that the goal that the companies were pursuing was clear. At the end of the $90 \mathrm{~s}$ and during the early $2000 \mathrm{~s}$, the implementation phase of the CPM methodologies took place, which was consolidated in the following years. Therefore, many companies have equipped themselves with a balanced scorecard by which monitor the level of their performance. In recent years, research has turned its attention to identifying a methodology to determine how a company can be managed through the measurement of its performance, how value can be obtained from 
the data extracted from the company, and which are the conditions for which they obtain the expected benefits following the adoption of systems for the CPM. In fact, it was concluded that the process necessary to measure company performance would result in an inefficient and ineffective use of resources if it was not possible to obtain information useful for defining the corporate strategy. Various data collection campaigns were conducted (for example the one conducted by the Metrus Group using 100 US companies as a sample) which made it possible to highlight significant differences, in relation to some types of services, between companies that adopt CPM systems and those that do not adopt.

The logic through which to implement a system for CPM in the company provides, first of all, the identification of the set of stakeholders and their needs and expectations. The satisfaction of these needs, often conflicting with each other, must guide companies in identifying their objectives, through the pursuit of which to ensure short-term profitability and long-term growth prospects. The second step consists in identifying the strategies to be implemented to meet the requests and needs of the stakeholders. If the stakeholders' requirements represent "what" to achieve, the strategies must answer the question constituted by the "how" to operate to obtain these results. In this regard, it should be noted that some studies have shown that $90 \%$ of managers make mistakes in implementing the strategies identified. It is therefore necessary to identify which processes are necessary for the company to implement the identified strategies. In fact, it often happens that internal processes within companies are not aligned with strategies.

At this stage, considerations can be made regarding the need to develop new processes and, in this case, to decide whether to operate through a Business Process Reengineering approach or by means of process improvements depending on the extent of the changes to be introduced. Having defined the tools by which apply the strategies, it is necessary to evaluate the capabilities that the company must have in order to improve its processes. In fact, in order to implement the processes required for the development of strategies, companies may be required to have personnel with skills that allow them to carry out the new tasks that they are required to acquire and to develop new infrastructures and technologies that allow them to align the business processes with the strategies. Finally, another aspect linked to stakeholders must be considered: the stakeholder contribution which constitutes the dual component of stakeholder satisfaction. Recent researches conducted in different industrial contexts has shown, for example, that companies operate more efficiently if they do not consider all their customers to be of equal importance. A possible distinction could be based on the level of profits that each of them guarantees. Customers, in fact, have no interest in being loyal and profitable for their suppliers. Their requirements are essentially made up of obtaining good quality products at low prices. It is in the company's interest to have loyal consumers who represent important sources of profit.

These parameters can be used to monitor the contribution of stakeholders to the development of corporate strategies. Furthermore, through this monitoring, a more effective and efficient use of company resources can be obtained. One could, for example, identify which category or group of customers is associated with a greater increase in performance as a result of actions carried out by the company and, as a function of this, guide 
corporate strategies. Similar reasoning applies to the staff employed, to suppliers and to the company's lenders.

This concept is illustrated in the diagram in figure 2 .

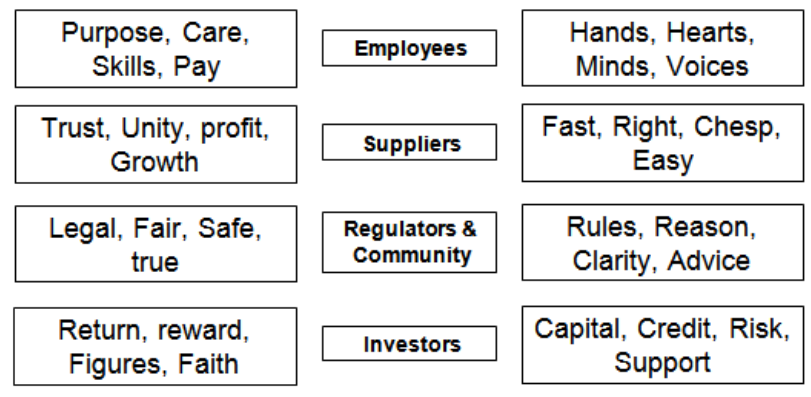

Fig.2: Stakeholder and Organization Wants and Needs

The logical path described is the one on which the Performance Prism is based, which represents an innovative approach to the CPM problem. It differs from that of the Balanced Scorecard and in some way represents an evolution. The elements from which this evolution is highlighted are constituted by a more careful analysis of the stakeholders and by a clear distinction between the object of the improvement represented by the satisfaction of the stakeholders (what) and the methodologies to be used to pursue this improvement, the strategies (how). To complete the overview on Corporate Performance Management, it is necessary to identify the key factors that allow a CPM system implemented effectively according to the guidelines defined above to lead the company to the expected results. Studies in the literature and interviews with company management have made it possible to identify the following factors, as founding elements for an effective and efficient application of CPM systems:

- Corporate Culture

- Alignment

- Review and Update

- Communication and Reporting

- Involvement of Employee

- Management Understanding

- Compensation Link

- Management Leadership and Commitment

- A clear balanced framework

- Agreement on strategy and Success Map

- Data Processes and IT support

- Target Setting

- Budget Link

- Management Support System

- Industry and Business

\section{Product traceability along the food production chain}

The ability of a company to trace a product along the production chain to which it belongs, also represents a measure of its ability to monitor its production process, the distribution process and the acquisition of materials from suppliers. A necessary condition to be able to trace a product is represented by having implemented an effective and efficient Information System in the company by means of which identify, collect and store the 
necessary data, allow the obtaining of useful information from them, make the information available to those who need it and provide the possibility of carrying out a drill down analysis with the aim of establishing cause-effect relationships between different phenomena. The traceability of the product can have a preventive purpose or be induced by the finding of anomalies relating to some quality requirements. The use of the word quality is deliberately generic. Non-compliance, in fact, can be considered both from the point of view of food safety, in the case of products aimed at this type of market, but also from the point of view, for example, of "defects" and punctuality of delivery. All the aspects listed above denote a lack of compliance with some customer requirements. This generic nature of the problem must make us reflect on the importance, from the point of view of business management, of having procedures that guarantee the traceability of products, through which the effectiveness and efficiency of companies in identifying and solving their problems and consequently their ability to generate profit. In the present paper, the concept of traceability will be treated only with reference to the food safety of products placed on the markets by companies. This meaning also gives to the concept of traceability an ethical connotation. The need to trace a product, in order to guarantee food safety, may be induced in one case by the need of a control body or the company itself to monitor the individual components of a product for statistical or preventive purposes or, in another case, from the finding by a consumer of some anomalies in the product. The distinction between these two scenarios depends on the different objectives to be achieved in the two cases and therefore on the different requirements that a system for the traceability of products must satisfy. In the first case, the traceability procedures must make it possible to disaggregate the components of a product in order to monitor them. A useful measure to identify the necessary degree of disaggregation is represented by the number of elements that make up the Bill Of Materials of a product. When the second situation occurs, the company's goal is to identify the cause of the anomaly found in order to avoid that other products in the future may be characterized by the same problems and, above all, to eliminate the possibility that other consumers may find them in products already placed on the market. To achieve these objectives, the procedure for the traceability of the product must consist of two phases: through the first, which could be defined "search for causes" and which proposes the same objectives described in the previous case, they must be followed backwards, along the entire supply chain, the stages of the production process that led to a defective product, in order to collect as much information as possible among that belonging to the following group: the raw materials of which it is composed, the suppliers used by the company for its production, the machinery from which it was processed, the operators who contributed to its realization and the time interval in which it was worked. This is in order to narrow down the field of possible causes of anomalies, with the aim of identifying them. Following this phase, the results of which are the input for the second phase, all products that may be characterized by the same type of defect must be eliminated from the markets. This phase could take the name of "cleaning the market". To perform this operation efficiently, it is necessary, first of all, to determine all the products that have used materials or have been processed by machinery identified as the cause of the anomaly found and to identify where these products have been delivered and offered for sale. It is evident that this second phase, unlike the first, also involves the distribution process. To understand the complexity of the problem, it is possible to refer to the diagram below which describes a generic process of production and 
distribution of a product to the customer (fig. 3). It happens, in fact, in processes characterized by such a scheme that the maximum degree of disaggregation regarding information useful for carrying out the "market cleaning" phase, is constituted by that deductible at the level of the delivery warehouse areas. This level of disaggregation is not sufficient to ensure an efficient procedure for eliminating defective products from the markets. The physiological discontinuity between the production and the distribution processes, which occurs in many companies due to the diversity of the product characteristics that are important in the two phases, make critical this second part of the traceability procedure. In particular, the difficulty lies in the ability to know where the goods produced have been delivered. With regard to this part of the traceability procedure, most of the efforts must be directed with the aim of integrating the information flow that guides the production process with that on which the distribution process is based. The difficulty of providing for this integration must be found, as will be discussed below, in the fact that the objectives to be reached through the distribution phase do not take into account, if not in a small part, the information coming from the production process.

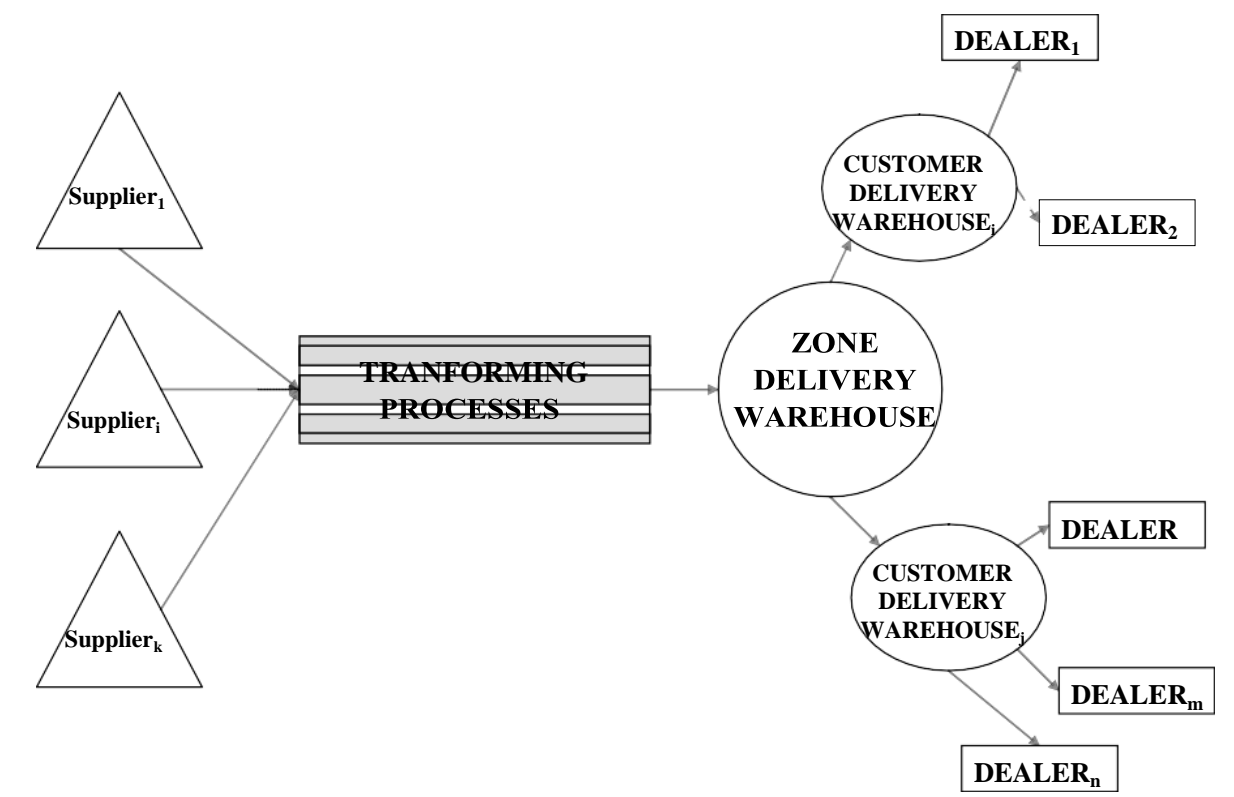

Fig.3: General scheme of a production process for the production and delivery of a product to retailers

\section{Corporate Performance Management System guided by the Product Traceability Regulations}

The process of implementing a system for measuring performance within a company consists of the steps described in the previous paragraphs. To take into account the legislation on product traceability, these steps must be adapted to the new objectives, in order to allow an efficient and effective implementation of a CPM system. Examples of possible indicators useful for this purpose will be provided below.

\section{Stakeholder Satisfaction}

The corporate stakeholders are generally attributable to the following categories: Customers, Suppliers, Employees, Investors and Legal Community. Customer satisfaction, as well as through the supply of high quality products and services at low prices and quickly, must also be pursued through the completeness, clarity and conciseness of the information relating to the product that is provided to them. By means of such information, in 
fact, the customer gains confidence in the manufacturer who proves to keep his product and production process under control. The company must select the information to be transmitted to the customer and such information must be more detailed the better the knowledge of the product that its customers on average are believed to have. This knowledge can be considered, in good approximation, a function of the simplicity of the production process that characterizes the product. Since the customer is not always able to perceive all the product information provided by the company due to the complexity of this information and the coding used by it, it could be useful, in order to evaluate the efficiency of the information exchange between company and customer, to evaluate the number of information perceived on average by customers, compared to that provided to them by the company when purchasing the product i.

$$
\text { Information Exchange Efficiency }_{i}\left(\text { IE }_{i}\right)=\frac{n r . \text { perceived }_{i} \text { information }_{i}}{\text { nr.total provided }} \text { information }_{\text {inform }} \text {. } 100
$$

Possible measures of the degree of customer satisfaction following this exchange of information are represented by the monitoring of the percentage change in product sales compared to the instant of time in which the requirements of the traceability legislation were implemented.

$$
\text { Sell Improvement } \operatorname{Ratio}_{i}\left(\operatorname{SIR}_{i}\right)=\frac{\left(\text { subsequent sales }_{i}-\text { previous sales }_{i}\right)}{\text { previous sales }_{i}} * 100
$$

A measure based on these parameters could, however, lead to wrong considerations in the event that there is an increase or decrease in the sale of products common to all operators present in the market, hence the need to use relative measures. Indeed, it would be useful to analyze the change in market share for each individual product sold by the company following the introduction of this new service.

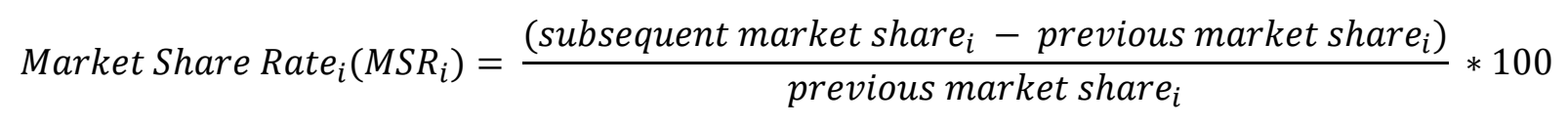

This analysis could be completed by comparing the quality and number of information provided to customers by the company and that provided to them by its competitors. This type of analysis, in fact, would be quite easy, based on the inspection of the competitors' finished product. As with the company / customer relationship, the company / supplier relationship is also affected by the traceability legislation. In fact, alongside the well-known requirements that determine the satisfaction of suppliers, first of all compliance with payment deadlines, there must also be added that concerning the company's ability to promptly trace the causes of any defects found on its products placed on the market and to know the place where they have been sold. The uncertainty on the part of the company in carrying out these operations would have negative consequences on suppliers since, in situations of uncertainty relating to the identification of the causes of anomalies, the supplier could be held unfairly responsible for any defects in the products. An indicator to measure the satisfaction of suppliers in relation to this aspect is the "degree of transparency" of the company, that is, the ratio between the amount of information relating to the material $\mathrm{j}$, component of the product I, transmitted by the supplier s still traceable in the product finished, compared to those supplied to the company by the supplier always in relation to the same material $\mathrm{j}$. 


$$
\text { Transparency Level }_{j-i}\left(T L_{j-i}\right)=\frac{\text { material }_{j} \text { information deductible from the product }_{i}}{\text { material }_{j} \text { information }_{\text {form }}} * 100
$$

Another indicator that could be used to measure supplier satisfaction is the ratio between the number of materials supplied to the company by the supplier s whose store is known and the total number of materials supplied by the supplier in question.

$$
\text { Company Transparency Level }_{j}\left(C T L_{j}\right)=\frac{\text { components }_{s} \text { with wellknown point of sale }}{\text { components }_{s}} * 100
$$

The personnel employed in the company in charge of production, transport and administration will have to change their duties in order to meet the requirements of the traceability legislation. Alongside the operational activities by which to guarantee the continuity of the production process, they will also have to operate so that the information characterizing each stage of processing, storage and transport is not lost. This will lead to an increase in the number of operations they will have to carry out. In most cases, the additional steps will be to load the data into a spreadsheet or database. Beyond these "manual" operations, they will have to learn and develop a new coding for the products. Employee satisfaction essentially depends on two factors: the degree of understanding they have in relation to the activities they perform and the incentives linked to the operations they carry out. These aspects must be measured in relation to the activities required to comply with the European legislation on traceability. This qualitative analysis could be conducted with the aid of a multiple-choice questionnaire by means of which information is obtained on the perception that the employees have regarding the importance and the evaluation by the company of the new operations that they are called to perform.

Following the implementation of the traceability legislation, the satisfaction of the company's lenders also passes through the analysis of the quantity of products that must be removed from the market in the event that a defect is found. The produced goods introduced and then removed from the market without being sold, negatively affect the company's profitability, as no income was obtained from products on which all the production and transport costs were charged. Similarly to what happened for suppliers, lenders (suppliers of financial resources for the company) are interested in knowing the relationship between the number of products or lots whose place of sale is known to the entire company portfolio. This indicator could be called Company Transparency Level

$$
\text { Company Transparency Level }(C T L)=\frac{\text { products with wellknown point of sale }}{\text { business portfolio }} * 100
$$

The degree of satisfaction of the lenders, of course, is also affected by the level of knowledge of the properties of the materials that make up a finished product. In this case it is necessary to measure the transparency of the data of the production process. In particular, it can be calculated the ratio between the number of data available upstream of the assembly process and those available once the finished product $\mathrm{i}$ has been obtained. This ratio can be calculated for each of the materials k constituting the finished product, regardless of whether they come from suppliers or are semi-finished products of the company. 


$$
\text { Transparency Level }_{k-i}\left(T L_{k-i}\right)=\frac{\text { assembled product }_{i} \text { data }_{k}}{\text { data }_{k}} * 100
$$

The Legal Community can be considered made up of three types of members with different interests. Institutional bodies, in this case the European Union, control bodies and public opinion. In the case of the European Union, it should be noted that its degree of satisfaction can be represented by a 0-1 function. Indeed, it is maximum if the constraints imposed by it are satisfied, while if this does not happen, its satisfaction is null. The degree of satisfaction of the control bodies depends on the way in which the company has complied with the constraints. In particular, it is a function of the analysis detail obtainable using the traceability procedure implemented in the company. An index for the measurement of this parameter can be provided by the ratio between the number of deductible information on the identifiable components in the product $\mathrm{i}$ when it is ready for sale to the customer, compared to the total number of information on the components of the product.

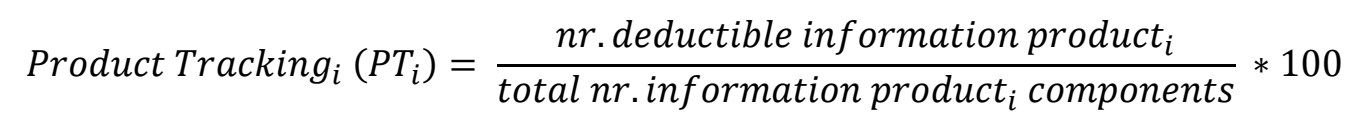

The role of the public opinion has played an ever increasing importance in recent years, becoming a non-institutional control body which, however, can decisively influence the judgment of the market on a given product, even though it is not composed exclusively by customers of the company. As a result of this, and the greater ease with which information can be exchanged thanks to the use of the internet, the company must pay particular attention to the level of public opinion satisfaction. Companies operating in the food market, then, must be particularly careful as the introduction of the legislation on traceability has increased the possibility of public opinion investigation which can more easily trace the materials that make up a product. In this case, his satisfaction can be measured with the same tools used to measure that of the institutional observers. Particular attention must be paid to the component materials of the products as even materials that comply with quality regulations can be a deterrent to purchasing a product. An example of what is meant by this concept is provided by GMOs which, even if they comply with quality regulations, are considered by a large part of the public to be harmful to people's health.

\section{Strategies}

The objectives to be pursued to achieve stakeholder satisfaction can be divided into two categories:

* have information available regarding the type and the origin of the materials making up the finished product, the machinery used during processing, the staff and the time interval in which the product was processed;

* have information available about the point of sale of each individual product.

The strategy to reach them must include the integration of the information flow characterizing the distribution phase with what regulates the production process. These flows, in fact, in many companies are independent from each other, despite the fact that they depend on each other. The production process, in fact, is affected by customer demand while the distribution of the products must take into account the characteristics of the products to be transported. Despite this physiological interaction, it may happen that some information characterizing a product 
and kept linked to it throughout the production process is lost. In particular, it happens that it is no longer possible to identify the links between the products and the information concerning their production process that have been correctly stored. This happens because product information is useful during the production phase, when the process is driven by the company, but is no longer useful during the storage and distribution phase of the finished product, during which the process is guided by the customer needs. Another reason for the loss of information is the different level and different aggregation parameters by which the products are processed during the production and the distribution phases. For example, the production can be managed by batches of such dimensions as to make the production process economical, during the distribution phase, however, the batches can be dismembered based on the demand of different customers. Thus, the information characterizing a lot can be dispersed, having no repercussions on the effectiveness of the distribution process. With the introduction of the product traceability legislation, it is important to know by which lot the customer demand is met. This procedure allows to determine where the products, or the lots obtained using a particular type of material, have been sold, allowing to activate the "cleaning of the markets" when it becomes necessary to collect all products with certain characteristics. In some cases, one may find it impossible to disaggregate a data. This can happen in an attempt to make the most of the production capacity of machinery or storage of warehouses. For example, in a bread production company, a silos for the storage of flours could have a capacity such that it needs to be filled with flours with the same characteristics from different suppliers, or with flours from the same supplier, but of different lots, i.e. produced in different time intervals. In the first case, the maximum disaggregation of the given flour is represented by the type used, since it is not possible to trace the supplier of the flour used in the production of a batch of bread. In the second case, however, it is possible to trace the manufacturer of the flour used in a particular product while the time interval that can be isolated is probably greater than that required for the production of a batch of flour. These last considerations shift the attention towards the procedures for the management of production which must take into account the dictates of the legislation for the traceability of the product.

\section{Processes}

In order to identify the phases of the company production process to which attention must be paid to facilitate the integration between the information flows that regulate the production and those that regulate the distribution, it is necessary to distinguish the procedures through which the information is added to the product and the phases during which the information that characterizes a particular product could be lost. Having previously defined the set of information that must characterize a product, it can be deduced that all the phases inherent in its processing implicitly add useful information for the traceability of the product itself. First of all, action must be taken so that this addition of information becomes an explicit fact. It is therefore necessary to define a rule for coding the information characterizing each step of the process. In addition, the information must remain associated with the product during its production until its consumption. This can be achieved, for example, by using barcode labels by which to identify products. This problem, however, is not easy to solve if it is not possible to use a label to be applied directly to the product that can be updated from time to time, or when the label is affixed to the primary packaging which is lost once taken out the product from its packaging. This situation is common in most of the 
processes involving food products. In this case it is necessary to have databases in which it is possible, using, for example, time parameters, to trace the materials, machinery and labor used to process a product. Once the ability to store and update the information relating to company output during the transformation process is guaranteed, care must be taken to ensure that this information is not lost. The phases of the process in which there could be a loss of information, especially if a label cannot be directly associated with a product, are those in which storage takes place. During the production process, three types of warehouses can be identified: that of raw materials, that of WIP and that of finished products. Since the temporal one could be a parameter on the basis of which the components of a product can be traced, the management of the warehouses should be of the FIFO type, in order to maintain the same temporal sequence throughout the transformation process. Another problem relating to warehouses concerns the size of the lots and consequently their composition. The goal is to create batches as homogeneous as possible and small in size. These characteristics must take into account the characteristics of warehouses, transport carriers and customer demand. This last requirement implies an evolution of the company towards lean systems and must be achieved through a reduction in the set-up times of the machinery. It is noted that the interventions necessary to comply with the traceability regulations are transversal and involve a large part of company processes.

\section{Capabilities}

In order to be able to improve its production processes or to develop new ones, in order to pursue the objectives defined by the needs of the stakeholders through the strategies established, it is necessary to identify the capabilities that the company must possess. Business capabilities can be distinguished in infrastructural, technological and skill. From the point of view of infrastructures, the traceability legislation does not require special interventions from the company. With regard to interventions related to technology, if information is transferred using barcodes, companies should equip themselves with barcode readers through which interpret and store information related to the product. Furthermore, the ability to process data must be guaranteed within the company through the availability of an adequate number of computers and the use of appropriate software tools. From the point of view of skills, operators must have a good knowledge of the IT tools that must be used to upload the data relating to the products, automatically or manually, in appropriate databases.

\section{Stakeholder Contribution}

According to the CPM guidelines, in addition to stakeholder satisfaction, stakeholder contribution must also be taken into consideration. Through this analysis we want to examine the contribution that stakeholders must provide to the company so that it can implement effective procedures for the traceability of products. According to this perspective, the performance of customers must be evaluated not only on the basis of their loyalty and their profitability, but also on the basis of the information they provide to facilitate this process. The traceability process, in fact, can also be triggered by customers. At the time of consumption of a good, they can identify anomalies in it and consequently induce an analysis by the company aimed at establishing the causes. In this process, the customer plays a fundamental role in providing the inputs for the analysis. The customer's performance can be measured on the basis of the relationship between the information it provides compared to that 
which has been provided in a clear and understandable way. The ability of customers to provide detailed information affects the efficiency of the traceability procedure. From the company's point of view, being efficient in traceability means being able, first of all, to identify the causes of an anomaly as quickly as possible and then to withdraw from the market a quantity of products that is as close as possible to the really defective one. The efficiency with which this process is conducted and, therefore, the reduction of the costs associated with it, justifies and intensifies the investments made by the company in traceability procedures. In the exposition relating to supplier satisfaction, it was noted how the supplier feels guaranteed by knowing that the company is able to perform the operations related to traceability effectively. The same meter is used by the company to measure the performance of the supplier with a view to product traceability. In fact, the company, in addition to wanting to know the supplier from which a product comes, also wants to be reassured that the supplier is able to trace a problem when this activity becomes necessary. Being able to measure the ability of a supplier in this area is a particularly complicated operation for the company that is unable to investigate the production process of one of its suppliers. The company, therefore, must be based on the extent of the information that the supplier provides together with the product that sells it. Obviously, this indicator must also take into account the perception of the complexity of the supplier's production process by the company. The company expects help, to carry out the traceability of the product, also from the staff employed in it. In fact, the production staff must make sure to update the characteristics of the product downstream of each processing, while the distribution workers must also work to ensure that the characteristics associated with each product are not lost during the storage phases of the finished product and transport. The ratio between the planned number of data relating to the product that must be available downstream of the production process and those actually available provides a measure of the performance of the production workers, while the number of characteristics known to the company concerning the product ready for sales to the customer compared to those available downstream of the production phase provide a measure of the performance of distribution employees. As for the performance of lenders, its measure is of a qualitative nature and must be aimed at establishing whether they make the necessary funds available to the company, in order to operate properly. Similar considerations apply to the Legal Community in all its components which must place admissible requests and constraints and have a behavior consistent with their requests.

\section{Conclusions}

Traceability has an importance that goes beyond solving problems related to food safety and represents a useful tool for quality management within the company. Hence the interest of companies to develop procedures and to make use of software tools capable of guaranteeing the traceability of products. In this article, the problem of traceability in the field of food safety was analyzed with particular attention. This is because the Regulation 178/2002 makes this problem particularly critical. The problem was addressed from the point of view of Corporate Performance Management in order to identify the objectives that companies must pursue, the actions they must implement to achieve them and the skills they must develop to remain in compliance with the dictates of this legislation. This approach is primarily based on the identification of a group of stakeholders who guide the company's strategies and allows for the effective and efficient implementation of the dictates of the legislation on 
product traceability. The analysis of stakeholders is of particular interest, as it highlights the need to introduce a broader vision beyond the customers' horizon. In this regard, it should be noted the importance for the purposes of supplier and customer selection of the analysis conducted on the performance of stakeholders. In particular, it can also be used to determine the intensity of the economic and financial resources involved in the development of procedures for the traceability of products. The size of the investments, in fact, must be commensurate with the expected benefits that can be obtained from them, and this is strongly conditioned by the performance of suppliers and customers on the level of which, unlike what happens for employees, the company has little chance to act. Measuring the performance of employees, on the other hand, can provide the company with useful information to activate actions aimed at increasing the level of staff loyalty, a condition at the basis of an increase in its profits. The considerations made in the present paper provide an idea of the difficulties that companies operating in the food markets must face in order to comply with the legislation on traceability but, at the same time, allow us to understand the advantages that can be obtained in the event that the implementation followed the guidelines provided by Corporate Performance Management, and more generally the importance of a CPM system for companies.

Finally, as an original contribution, the author proposes to make a terminological differentiation between the information collection and recording system (traceability) and the process to be implemented, if a qualitative problem arises, to trace the causes that generated it (retrieval):

Traceability: means the totality of data and operations that is capable of maintaining desired information about a product and its components through all or part of its production and distribution chain. It is obtained mainly by the proper identification of the product / service and by the effective record in retrievable documents;

Retrieval: means the process that goes back in the supply chain to search for the event that triggered the deviation from what was expected. Therefore, the "retrieval" is the comeback that is the capability to trace the history, application and / or location of the product / service / document considered, by means of the "traceability".

\section{Bibliography}

Barge, P., Gay, P., Merlino, V., \& Tortia, C. (2013). UHF-RFID solutions for logistics units management in the food supply chain. Journal of Agricultural Engineering, 44(s2). https://doi.org/10.4081/jae.2013.301

Barge, P., Gay, P., Merlino, V., \& Tortia, C. (2017). Passive ultra high frequency radio frequency identification systems for single-item identification in food supply chains. Journal of Agricultural Engineering, 48(1), 28-35.

Bourne, M., Franco, M. (2003). Corporate Performance Management: latest thinking on performance management, the achievable benefits and practical advice on the way forward. SAS edition

Comba, L., Dabbene, F., Gay, P., \& Tortia, C. (2013). Open problems in traceability: from raw materials to finished food products. Journal of Agricultural Engineering, 44(s2). https://doi.org/10.4081/jae.2013.272

Coscia, G. (2002). "Il regolamento CE 178/2002: le novità per la sicurezza alimentare” Intervento alla tavola rotonda "Sicurezza alimentare: novità attese e riflessi applicativi". Camera di Commercio di Alessandria 
Farné, S. (2010). Qualità Operativa. Farnco Angeli Editore, Milano

Giametta, F., Sciarrone, G. (2008). An integrated technological traceability model in the olive growing production chain. Journal of Agricultural Engineering, 39(4), 19-26. https://doi.org/10.4081/jae.2008.4.19

Kaplan R.S., Norton D.P. (1996). Translating Strategy into Actions: The Balanced Scorecard. Harvard Business School Press

Larizza A.C. (2004). Il software ridisegna l'agroalimentare. http://www.ilsole24ore.it

Neely A., Adams C.Perspectives on Performance:The Performance Prism.

http://www.exinfm.com/pdffiles/prismarticle.pdf 